\title{
Compulsivity in obsessive-compulsive disorder and addictions
}

Martijn Figee $^{\mathrm{a}}$, Tommy Pattij ${ }^{\mathrm{b}}$, Ingo Willuhn ${ }^{\mathrm{a}, \mathrm{c}}$, Judy Luigjes ${ }^{\mathrm{a}}$, Wim van den Brink ${ }^{\mathrm{a}, \mathrm{d}}$, Anneke Goudriaan $^{\mathrm{a}, \mathrm{d}}$, Marc N. Potenza ${ }^{\mathrm{e}}$, Trevor W. Robbins ${ }^{\mathrm{f}}$, Damiaan Denys ${ }^{\mathrm{a}, \mathrm{c}}$

${ }^{a}$ Academic Medical Center, Department of Psychiatry, Amsterdam, the Netherlands

${ }^{b}$ Neuroscience Campus Amsterdam, Department of Anatomy and Neurosciences, VU University Medical Center, Amsterdam, The Netherlands.

${ }^{c}$ The Institute for Neuroscience, an institute of the Royal Netherlands Academy of Arts and Sciences, Amsterdam, The Netherlands

${ }^{d}$ Amsterdam Institute for Addiction Research, Amsterdam, the Netherlands

${ }^{e}$ Department of Psychiatry, Yale University School of Medicine, New Haven, CT, United States; Department of Neurobiology, Yale University School of Medicine, New Haven, CT, United States; Child Study Center, Yale University School of Medicine, New Haven, CT, United States. ${ }^{f}$ Department of Psychology and Behavioural and Clinical Neuroscience Institute, University of Cambridge, Cambridge, United Kingdom

Please address all correspondence to:

Damiaan Denys, M.D., Academic Medical Center, University of Amsterdam, Department of Psychiatry, Postbox 75867, 1070 AW Amsterdam, The Netherlands.

E-mail: d.denys@gmail.com

\section{ABSTRACT}

Compulsive behaviors are driven by repetitive urges and typically involve the experience of limited voluntary control over these urges, a diminished ability to delay or inhibit these behaviors, and a tendency to perform repetitive acts in a habitual or stereotyped manner. Compulsivity is not only a central characteristic of obsessive-compulsive disorder (OCD) but is also crucial to addiction. Based on this analogy, OCD has been proposed to be part of the concept of behavioral addiction along with other non-drug-related disorders that share compulsivity, such as pathological gambling, skin-picking, trichotillomania and compulsive eating. In this review, we investigate the neurobiological overlap between compulsivity in substance-use disorders, OCD and behavioral addictions as a validation for the construct of compulsivity that could be adopted in the Research Domain Criteria (RDoC). The reviewed data 
suggest that compulsivity in OCD and addictions is related to impaired reward and punishment processing with attenuated dopamine release in the ventral striatum, negative reinforcement in limbic systems, cognitive and behavioral inflexibility with diminished serotonergic prefrontal control ${ }_{2}$ and habitual responding with imbalances between ventral and dorsal frontostriatal recruitment. FThese frontostriatal abnormalities of compulsivity are promising targets for neuromodulation and other interventions for OCD and addictions. We conclude that compulsivity encompasses many of the $\mathrm{RDoC}$ constructs in a trans-diagnostic fashion with a common brain circuit dysfunction that can help identifying appropriate prevention and treatment targets.

\section{Introduction}

Compulsivity in obsessive-compulsive disorder (OCD) is related to the feelings of limited voluntary control and being compelled to perform repetitious, self-defeating behaviors (Denys, 2011; Robbins et al., 2011). Based on analogies between these compulsive characteristics of OCD and the cognitive and behavioral characteristics of substance-use disorders, some researchers have proposed to view OCD as a behavioral addiction (Holden, 2001; Denys et al., 2004), together with several other non-substance disorders, including pathological gambling, trichotillomania, skin-picking, compulsive eating, compulsive computer use, compulsive sexual behavior, and compulsive buying (Holden, 2001; Grant et al., 2006). The study of different aspects of compulsivity and their neural correlates in these disorders may help to test the behavioral-addiction paradigm and to define shared brain networks.

In OCD, compulsivity represents a key symptom. Although patients suffering from OCD may present with various types of obsessions and compulsions that may be accompanied by 
other symptoms such as anxiety and depression, a compulsive drive with a perceived loss of control appears to be a crucial factor.

In addiction, two theories describe the development from initial (impulsive) drug use to chronic (compulsive) drug taking. One theory forwarded by Everitt and Robbins (2013) emphasizes the progression from initial action-outcome (reward-based) learning to stimulusresponse (habitual) learning. Another theory forwarded by Koob and Le Moal (2005) emphasizes the transition from positively reinforced drug-taking (impulsive stage) to negatively reinforced (removal of aversive state) compulsive drug-use (compulsive stage). These theories are not mutually exclusive, but they do suggest different processes in the development of compulsivity.

In behavioral addictions, compulsivity is less well studied, especially compared to other relevant constructs such as impulsivity. On the $1^{\text {st }}$ of May 2015 , the search terms compulsivity and behavioral addiction resulted in 68 Pubmed listings, whereas the terms impulsivity and behavioral addiction resulted in 6268 listings.

Like impulsivity, compulsivity may be decomposed into various factors with a mainly cognitive, affective or motivational nature. First, compulsivity, as engagement in self-defeating repetitive behaviors, hints at impaired reward and/or punishment processing. Second, the diminished ability to stop or divert unwanted ideas and actions suggests the presence of cognitive and behavioral inflexibility. Third, habitual responding and diminished goal-directed control suggests excessive habit-learning. In this narrative review, we will study the neural overlap of these different aspects of compulsivity in OCD, substance-use disorders and behavioral addictions, including human imaging studies and animal models of compulsive behavior and associated neurotransmitters. Our goal is to use these data to define which neural processes are 
central to compulsivity and to use this knowledge as a pathophysiological validation for the possible adoption of compulsivity in the Research Domain Criteria (RDoC; Insel et al., 2010; Casey et al. 2013).

\section{Neurocognitive factors}

\section{Reward processing}

Compulsivity in OCD and addiction may in part be explained by dysfunctional brain reward systems, driving the development of a restricted behavioral repertoire at the cost of healthy rewarding actions and a relative failure to switch to more adaptive, goal-directed behaviors. Indeed, patients with OCD displayed attenuated reward anticipation activity in the ventral striatum compared to controls (Figee 2011 and 2014), which matches blunted reward anticipation signals of the ventral striatum in alcohol (Wrase et al.,2007), nicotine (MartinSoelch et al., 2003; Bühler et al., 2009) and cannabis dependence (van Hell et al., 2010), in a behavioral addiction like pathological gambling (Reuter et al., 2005; de Greck et al., 2010; Balodis et al., 2012; Choi et al., 2012), and in binge-eating disorder (Balodis et al., 2013). However, not all studies of substance-use disorders and behavioral addictions show this pattern. For example, mixed findings were reported in cocaine dependence (Balodis and Potenza, 2015) and pathological gambling (Van Holst et al., 2010 and 2012). Blunted striatal responsiveness in OCD is paralleled by increased striatal activity in response to symptom-provoking stimuli (Menzies et al., 2007; Rotge et al., 2008), which appears to be analogous to ventral striatal hyperactivation associated with disorder-specific stimuli in drug addiction (Wrase et al., 2007; Diekhof et al., 2008; Kühn et al., 2011). Similar findings have been observed in some (Hollander et al., 2005; van Holst et al., 2012), but not all (Potenza et al. 2003) studies of pathological 
gambling and may also hold true for food consumption and weight gain (Stice et al., 2010). This suggests that the ventral striatum may be less responsive when recruited for healthy reward processing due to its bias toward drugs in addiction, and due to its bias to disease-specific stimuli in OCD and behavioral addictions. Importantly from a treatment perspective, effective deepbrain stimulation (DBS) for OCD has been related to a normalization of anticipatory reward responses in the ventral striatum (Figee et al, 2014).

It should be noted that there are also diverging reward-processing findings. First, some studies showed no blunted striatal reward anticipation in OCD (Jung et al., 2011; Choi et al., 2012), or blunted reward anticipation only in prefrontal regions (Kaufmann et al., 2013). Second, a more generalized pattern of diminished activity in both prefrontal and striatal areas during reward anticipatory as well as outcome phases is usually found in drug addiction (Hommer et al., 2011) and binge-eating disorder (Balodis et al., 2013). These conflicting data do not challenge a common reward hypothesis of compulsivity, but hint at some heterogeneity of reward processing. Patients with OCD may have primarily difficulties in estimating the value of a potential rewarding situation rooted in striatal dysfunction, whereas in substance-use disorders and behavioral addictions, outcome-related or consummatory aspects of reward processing in the medial prefrontal cortex may also impaired.

In summary, compulsivity in OCD and addictions is related to impaired reward processing in the ventral striatum, which may in part mediate compulsive behaviors at the cost of healthy rewarding actions. 


\section{Punishment sensitivity}

Individuals engaged in compulsive behaviors may be less capable of noticing its selfdamaging consequences, which suggests impairment of neural processes underlying harm avoidance and sensitivity to punishment. Although studies in OCD confirm dysfunctional processing of punishments, the results are diverging, with brain activity during monetary loss anticipation in OCD patients being either normal (Figee et al., 2011) or increased in the medial prefrontal cortex (Kaufmann et al., 2013), or decreased in the ventral striatum (Jung et al., 2011). The latter finding suggests decreased striatal sensitivity to punishment in OCD, which matches with decreased striatal loss-anticipation signals in pathological gambling (Choi et al., 2012) but not in alcohol addiction (van Holst et al., 2014). The study by Choi et al (2012) also found that pathological gamblers and OCD patients share decreased loss-anticipation signals in the insula. The insula is involved in the mediation of bodily interoceptive signals for processing negative cues, and this region has also been associated with drug craving (Naqvi et al., 2007). Therefore, we speculate that insula dysfunction may be involved in compulsivity in OCD and addictive behaviors contributing to a diminished ability to foresee the negative consequences of compulsive actions.

Animal models have arguably provided more convincing links between compulsive drugseeking and impaired punishment-sensitivity. Compulsive drug-seeking in these models is oftentimes operationalized by pairing an operant drug-seeking response that eventually leads to drug access with the delivery of an aversive event (e.g., foot shock), aiming at modeling the human symptom of seeking access to a drug despite the knowledge of negative consequences. Importantly, similar to humans, only a subset of animals allowed access to drug in this model develops compulsive drug seeking (Pelloux et al., 2007 and 2012; Deroche-Gamonet et al., 2004; 
Vanderschuren and Everitt 2004). Exclusively in these "addicted" animals, prolonged cocaine self-administration was shown to permanently impair long-term depression (LTD) in the ventral striatum (Kasanetz et al., 2010), thus potentially cementing rigid, compulsive drug seeking by eradicating synaptic plasticity in a brain region central to reward-related learning. In addition, pyramidal neurons in the prelimbic cortex that project to the ventral striatum have been shown to be hypoactive in animals that seek cocaine despite foot-shock punishment, but less so in animals sensitive to punishment (Chen et al., 2013). Conversely, compensating for this hypoactivity, optogenetic stimulation significantly prevented compulsive cocaine seeking, whereas optogenetic inhibition significantly increased compulsive cocaine seeking (Chen et al., 2013). Furthermore, it was shown that pharmacological inactivation of the prelimbic cortex, but not the orbitofrontal cortex, increased compulsive drug-seeking in animals with limited access to cocaine in a conditioned suppression model (Limpens et al., 2014). However, inconsistent results were reported by a lesion study that targeted the anterior cingulate, prelimbic, infralimbic, orbitofrontal and anterior insular cortices without altering compulsive drug-seeking (Pelloux et al., 2013). This indicates that prefrontal cortical, top-down inhibitory control over limbic-striatal mechanisms of drug-seeking behavior do not necessarily control all aspects of compulsive drugseeking, but it may nonetheless be implicated in conditioned suppression and shock suppression after compulsivity has developed. In contrast, Pelloux et al. (2013) report that lesions of a projection region of the prelimbic cortex, the basolateral amygdala, did increase compulsive drug-seeking. Interestingly, inactivation of the connected central nucleus of the amygdala induced robust resistance to punishment in rats with prolonged access to cocaine (Xue et al., 2012). Finally, inactivation of sensorimotor striatal areas that are not directly connected to the 
above-described limbic neural substrates can also lead to inhibition of compulsive drug seeking (Jonkman et al., 2012).

In summary, compulsive drug seeking may be associated with dysfunctional neural processing of punished behavior in ventral corticostriatal pathways, with some evidence suggesting similar impairments underlying compulsivity in OCD and pathological gambling.

\section{Negative reinforcement}

Compulsive behaviors may be performed to avoid aversive or anxiety-inducing outcomes. Indeed, a prominent theory in addiction research emphasizes the increasingly important role of negative reinforcement when drug taking becomes more compulsive over time (Koob 2015). In many patients drug taking is initially driven by its pleasurable effects, however over time their motivation seems to shift increasing the role of negative reinforcement that accompanies the development of compulsive drug use. Negative reinforcement that can drive drug use includes removal of an aversive state, whether this is physical withdrawal symptoms or a negative emotional state such as anxiety, stress or depression. There are even addicted patients who report never to have experienced pleasure and for who negative reinforcement like relief of stress or coping with negative emotions was their main drive throughout the course of drug use (Heilig et

al. 2010; Kennett et al 2013). Recruitment of anti-reward brain systems associated with aversive or stress-like states may underlie negative reinforcement in compulsive drug use. An important region implicated in these anti-reward systems is the extended amygdala (bed nucleus stria terminalis, BST) and more recently also the lateral habenula. Adaptations of these systems persist during and often beyond drug abstinence creating a condition of chronic dysphoria and increasing the risk relapse in a (compulsive) attempt to self-medicate this unwanted condition 
(Koob 2005; Vollstädt-Klein 2010). In addition, medial prefrontal-amygdala circuits involved in fear conditioning have also been implicated in persistent drug-seeking behavior (Peters et al, 2009). Similarly, in chronic problem gambling, excessive responses in the amygdala and insula may be linked to craving elicited by gambling pictures (Goudriaan et al, 2010), suggesting that negative reinforcement circuits could also have a role in compulsivity in behavioral addiction.

In many OCD patients negative reinforcement is an important drive of their compulsions from the start of the disorder. Traditionally, OCD is viewed as an anxiety disorder and for many patients the need to reduce anxiety or stress contributes to the persistence of the compulsions as supported by experiments that show decreases in anxiety or discomfort when patient are allowed to execute compulsive behavior after being exposed to symptom provoking situations (Rachman, et al 1976). However, contrary to findings in drug addiction, brain anti-reward systems such as the BST or lateral habenula have not yet been directly linked to OCD. Nevertheless, scheduleinduced polydipsia in rats, which might model aspects of human compulsivity, is associated with changes in the firing behavior of BST neurons (Welkenhuysen et al., 2013). In addition, the BST is currently being investigated as a DBS target for OCD (Nuttin et al, 2013), although effective ventral striatal DBS for OCD did not affect BST-related contextual anxiety (Baas et al, 2014). Also note that not all OCD patients report anxiety or stress and that negative reinforcement may contribute differently to the compulsions of OCD patients. In some cases of OCD, compulsive behaviors may start with anxiety and harm avoidance but gradually evolve into more habitual or impulsive responding with progression of the disease (Kashyap et al. 2012). In other cases, OCD may develop first as a propensity to compulsive behaviors, followed by anxiety and obsessive thoughts in response to these compulsive urges (Robbins et al., 2011). In line with the latter notion, structural and functional imaging studies in OCD and case-studies of acquired OCD after 
brain injuries have often failed to demonstrate clear pathology of the limbic system such as

found in anxiety disorders, but rather indicate that compulsivity may primarily stem from basal ganglia-prefrontal dysfunction (Whiteside et al., 2004; Radua et al., 2010; Figee et al, 2013).

In summary, compulsivity in addictions and OCD may in part be driven by negative

reinforcement, i.e. avoidance of dysphoria, stress or anxiety, with underlying abnormalities in

brain anti-reward and anxiety circuits, such as BST, amygdala and medial prefrontal cortex.

Cognitive and behavioral flexibility

Cognitive and behavioral inflexibility represent core features of compulsivity in OCD

(Chamberlain et al., 2006; Menzies et al., 2007), substance-use disorders (Izquierdo and Jentsch 2012; Ersche et al., 2008; van Holst et al., 2011) and some behavioral addictions (Goudriaan et al., 2006; Vanes et al., 2014). Contingency-related flexibility refers to the adaptation of behavior or cognitive strategies after positive or negative contingencies. Contingency-related flexibility has been linked to the orbitofrontal cortex (OFC) (Bechara et al., 2000). Abundant evidence implicates abnormalities of the OFC in OCD, such as decreased OFC volume and increased OFC symptom-related activity. Probabilistic reversal-learning tasks tap into the construct of contingency-related flexibility, and OCD patients compared to controls demonstrate defective OFC recruitment during these tasks (Remijnse et al., 2006; Chamberlain et al., 2008; Freyer et al., 2011). Similarly, substance-use disorders have been associated with reduced OFC volume (Franklin et al., 2002), OFC hyperactivation during drug taking and dysfunctional reversallearning OFC responses (Izquierdo and Jentsch 2012). Moreover, a study directly comparing OCD and stimulant-dependent individuals showed that compulsive symptom scores were significantly correlated with reduced orbitofrontal connectivity in both groups (Meunier et al., 
2012). Finally, diminished reversal-learning speed along with dysfunctional OFC responses during reversal-learning have also been found in individuals with pathological gambling (de Ruiter et al., 2009; Vanes et al., 2014).

Cognitive flexibility can also be measured with attentional set-shifting tasks in which attention is required to switch between multiple stimuli or tasks, requiring activation of the ventrolateral prefrontal cortex (Hampshire and Owen, 2006). Impaired set-shifting may promote perseveration and compulsive actions (Stalnaker et al., 2009). Set-shifting is found to be impaired in adult patients with OCD (Watkins et al., 2005; Chamberlain et al., 2006) and in pediatric OCD, which was associated with decreased frontostriatal activation (Britton et al., 2010). Comparable set-shifting impairments have also been found in individuals with gambling problems (Goudriaan et al., 2006; Odlaug et al., 2011; but see: Boog et al., 2014). On the other hand, set-shifting was intact in individuals with compulsive buying (Derbyshire et al., 2014). Finally, impaired set-shifting was also reported in individuals with opioid- (Ornstein et al., 2000) and stimulant- (Woicik et al., 2011) use disorders.

The neural correlates of behavioral flexibility have also been widely studied in animals using reversal-learning as well as attentional set-shifting tasks. Results from these studies confirm that corticostriatal circuits comprising the OFC, medial prefrontal cortex and striatum are implicated in behavioral flexibility (Clarke et al., 2008; Izqueirdo and Jentsch 2012). Furthermore, these models suggest that reversal-learning impairments may be linked specifically to dysfunction of serotonin in the OFC (Clarke et al., 2004, 2005, 2007) and dysfunction of dopamine in the striatum (Clarke et al., 2011), with selective serotonin reuptake inhibition (citalopram) rescuing behavioral flexibility via normalization of the OFC serotonergic tone (Barlow et al., 2015). 
In summary, cognitive and behavioral inflexibility appear to be shared aspects of compulsivity in OCD and addictions reflecting corticostriatal dysfunction, in particular impaired serotonergic top-down control of orbitofrontal and ventrolateral prefrontal cortices.

\section{Habit learning}

Habits can be defined as automatic, inflexible behaviors performed regardless of their consequences. Although it has long been speculated that habits may be a hallmark of OCD, excessive habits were first demonstrated in animal models of addiction in association with defective goal-directed behaviors that are mediated by frontostriatal mechanisms (Everitt and Robbins 2005; Everitt et al., 2008). These animal studies suggest a gradual progression from hedonic to habitual drug use over time associated with a shift from recruitment of ventral to more dorsal regions of the striatum (e.g., Belin and Everitt, 2008; Willuhn et al., 2012). One imaging study in humans suggested some indirect support for this ventral to dorsal shift by showing increased cue-induced activity in the ventral striatum in social drinkers and increased cueinduced activity in the dorsal striatum in heavy drinkers (Vollstädt-Klein et al., 2010). The first study directly investigating habits in addicted humans confirmed the presence of an imbalance between goal-directed and habitual control and between ventral and dorsal frontostriatal recruitment (Sjoerds et al., 2013). Patients with alcohol dependence compared to healthy controls showed a decrease in goal-directed learning associated with decreased activity in the ventromedial prefrontal cortex and the anterior putamen and an increase in habit learning associated with increased activity in the posterior putamen. Moreover, ventromedial prefrontal cortex activation (goal-directed learning) was negatively associated with alcohol dependence duration. Excessive habit learning was also demonstrated in OCD (Gillan et al., 2011). However, 
contrary to addiction, recent neuroimaging data do not support a ventral to dorsal transition underlying habit formation in OCD, but rather hyperactivation of the ventral striatum (caudate) leading to impaired goal-directed control over behavior (Gillan et al., 2014). In accordance with a shared dysfunction of these motivational brain systems in various disorders of compulsivity, lower gray-matter volumes of the caudate and medial orbitofrontal cortex were associated with excessive habit formation in OCD patients as well as in individuals with stimulant addiction and individuals with binge-eating (Voon et al., 2014).

Inappropriate habitual and repetitive responding in experimental animals resulting, for instance, from defective feedback mechanisms can be assessed in instrumental-learning tasks such as the so-called "signal-attenuation" procedure (Joel and Avisar, 2001). In this particular task, rats are trained to withhold lever pressing in response to signals that previously indicated food but have now been extinguished (signal attenuation). Importantly, in line with the therapeutic efficacy in OCD patients (Fineberg et al., 2012), selective serotonin reuptake inhibitors have been found to reduce the expression of compulsive-like behavioral responding in this task (Joel and Doljansky, 2003; Joel et al., 2004). In terms of the underlying brain circuits mediating compulsive-like responding in the signal-attenuation task, the OFC and basal ganglia nuclei such as the subthalamic nucleus and globus pallidus appear crucial (Albeda and Joel, 2012).

In summary, habitual behaviors that are performed regardless of their consequences may be central to compulsivity in OCD and addictions, reflecting imbalances between ventral and dorsal frontostrial recruitment. 


\section{Frontostriatal connectivity}

In line with a general dysregulation of the frontostriatal network in compulsivity, restingstate functional imaging studies have consistently demonstrated excessive functional connectivity between the striatum and the prefrontal cortex in OCD patients (Harrison et al., 2009 and 2013; Sakai et al., 2011; Figee et al., 2014) and positive correlations with disease severity (Harrison et al., 2009). Similarly, opioid dependence is associated with increased frontostriatal connectivity (Upadhyay et al., 2010), and a study in cocaine users found this frontostriatal hyperconnectivity to be positively correlated with compulsive aspects of drug use (Hu et al., 2015). Thus, excessive frontostriatal connectivity may be a common neural substrate of compulsivity in OCD and substance-use disorders. Importantly, frontostriatal connectivity may be normalized with DBS of the ventral striatum and with repetitive transcranial magnetic stimulation (rTMS) of the medial prefrontal cortex. Moreover, these normalizations also correlate with obsessive-compulsive symptom improvement (Figee et al., 2014; Dunlop et al., 2015). Prelimary evidence suggests that the effects of DBS and rTMS in individuals with substance-use disorders depend on similar changes in frontostriatal connectivity (de Ridder et al., 2011; Valencia-Alfonso et al., 2012).

\section{Neurotransmitters}

\section{Dopamine}

Results from studies assessing dopamine are in accordance with the reward circuitry as a potential link between compulsivity in OCD and addictions. Receptor-binding studies indicate hyperactivity of the striatal dopaminergic system in OCD, with decreased striatal availability of dopamine $\mathrm{D}_{1}$ receptors (Olver et al., 2009) and $\mathrm{D}_{2}$-like receptors (Denys et al., 2004; Perani et 
al., 2008) in patients versus controls, which is also found in individuals with substance-use disorders (Volkow et al., 2009) and in some studies with obese patients (Wang et al., 2001; Volkow et al., 2008; de Weijer et al., 2011). In addicted individuals, low levels of dopamine $\mathrm{D}_{2}$ like receptors are related to greater craving responses (Volkow et al., 2009) and speculatively, low levels of dopamine $\mathrm{D}_{2}$-like receptors in OCD could drive compulsions to overcome feelings of anxiety and discomfort. In line with this hypothesis, OCD patients display excessive ventral striatal activity related to loss avoidance (Jung et al., 2011).

The acute reinforcing effects of drugs of abuse have been linked to activation of the mesolimbic dopamine system (Koob and Volkow, 2010). Imaging studies in humans have convincingly shown the presence of dopamine release in the ventral striatum after smoking (Brody et al., 2009) and stimulant use (Volkow et al., 1995), with mixed results for alcohol and cannabis use (Bossong et al., 2009; Heilig et al., 2010; Kuepper et al., 2013) and negative findings for heroin (Daglish et al., 2008). Dopamine release in the ventral striatum is important for focusing on potential alerting and rewarding environmental stimuli that can be used for modulation of behavior by reinforcement-related learning (Schultz, 1998). Chronic drug-induced dopaminergic hyperactivity could compromise dopaminergic responsiveness to natural rewards. Indeed, amphetamine-induced $\mathrm{D}_{2}$-like-receptor displacement, mimicking natural dopamine release, is attenuated in drug addiction (Volkow et al., 1997 and 2012; Martinez et al., 2012) and probably also in obese patients (van de Giessen et al., 2012). In OCD patients, the only amphetamine-challenge imaging study to date revealed no significant blunting of dopamine release (Denys et al., 2013), although plasma investigations suggest attenuated apomorphineinduced dopamine release in some patients (Pichot et al., 1996; Brambilla et al., 1997). In pathological gambling, increased rather than diminished dopamine release was demonstrated 
recently (Boileau et al., 2014). In addition to impaired natural reward sensitivity, attenuated dopamine release may also reduce sensitivity for drug rewards resulting in compulsive drug taking and drug seeking (Berridge et al., 2007; Robinson and Berridge, 2008; Rothkirch et al., 2012; Volkow et al., 2011) or even habitual use as an automatic response to internal or external stimuli (Everitt et al., 2008). Medial-caudate-dopamine-depleted monkeys were impaired in their ability to reverse stimulus-reward associations (Clark et al., 2011). In stimulant-dependent humans, dopaminergic enhancement with the dopamine $\mathrm{D}_{2}$-like agonist pramipexole reversed abnormal perseverative responding and associated caudate dysfunction; however, no perseverative abnormalities or pramipexole-induced changes were observed in OCD patients (Ersche et al., 2011). No molecular imaging studies are currently available that have tested the role of dopamine specifically with habit paradigms.

Recent evidence from animal models implicates dopamine $\mathrm{D}_{1}$-like receptors and NMDA receptors underlying compulsive-like responding in signal-attenuation tasks (for review, see Albeda and Joel 2012). Comparable to the signal-attenuation procedure measuring inappropriate repetitive behavioral responses, compulsive-like behavioral responses may also be provoked by repeated challenges with dopaminergic agents. For instance, repeated exposure to the dopamine $\mathrm{D}_{2}$-like-receptor agonist quinpirole is found to robustly induce repetitive checking behavior (Szechtman et al., 1998) and more recently in a novel instrumental-learning task (Eagle et al., 2014), the latter allowing for further determination of the cognitive processes that might underlie this checking behaviour. These models stress the importance of dopamine transmission in the development and expression of compulsive-like behaviour. For example, the dopamine $\mathrm{D}_{2}-$ likereceptor antagonist sulpiride has been found to remediate quinpirole-induced compulsive-like behaviour (Eagle et al., 2014). Lesioning and DBS studies have indicated that quinpirole-induced 
repetitive checking involves the ventral striatum and subthalamic nucleus (Mundt et al., 2009; Winter et al., 2008b), whereas in control subjects (vehicle-treated animals) lesions of the ventral striatum and the OFC were found to induce different aspects of repetitive checking (Dvorkin et al., 2010). Finally, quinpirole-induced compulsive lever pressing correlated with diminished dopamine signaling in the ventral tegmental area, which was proposed to reflect lower base-line dopamine burst firing and higher stimulus-driven dopamine activity as a characteristic of compulsivity (Sesia et al., 2013).

In summary, despite some outcome variability these data convincingly stress the importance of dopaminergic mesolimbic, corticostriatal and basal ganglia pathways in perseverative responding and compulsive checking.

\section{Serotonin}

OCD is associated with decreased presynaptic serotonin transporter availability in thalamic and midbrain-pons regions, along with increased postsynaptic serotonin $\left(5-\mathrm{HT}_{2} \mathrm{~A}\right)$ receptor availability in cortical areas, indicating diminished serotonergic input into frontosubcortical circuits (for review, see Figee et al., 2010). Müller \& Homberg (2015) suggest that diminished reactivity of the serotonergic system is also involved in the transition to compulsive drug use since studies have shown that carriers of the short allele of the serotonin transporter gene (5-HTTLPR S-allele carriers) are more likely to exhibit alcohol and drug (e.g., mostly cocaine) dependence (Enoch et al., 2012). The same serotonin transporter gene is arguably the best-supported risk variant for OCD, though this relates to the long (high-expressing function) alleles instead of the short alleles associated with addiction (Walitza et al., 2014). 
Animal studies have highlighted specific involvement of the $5 \mathrm{HT}_{2 \mathrm{C}}$ receptor in modulating compulsive-like responding in signal-attenuation tasks (Flaisher-Grinberg et al., 2008). In addition, rats that compulsively seek cocaine show decreased serotonin utilization in several forebrain regions including ventral and dorsal parts of both the prefrontal cortex (PFC) and the striatum, as well as in the amygdala (Pelloux et al., 2012). This compulsive drug seeking was reversed by the facilitating of serotonin transmission using a serotonin reuptake inhibitor or

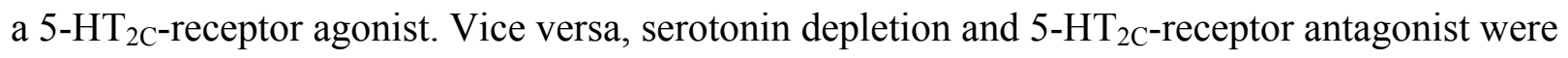
sufficient to produce compulsive drug seeking in rats without prolonged drug-access (Pelloux et al., 2012).

\section{$G A B A$}

It has been suggested that the development of compulsive drug taking is mediated by impaired GABA-ergic inhibition of drug-related dopamine release (Goodman et al., 2008; Vlachou and Markou, 2010). Indeed, $\mathrm{GABA}_{\mathrm{B}}$-agonizing agents are able to inhibit reinforcing effects of drugs and are promising treatment candidates for addictions (Filip et al., 2015). Impairment of GABA-ergic systems has also been found in OCD; e.g., decreased plasma GABA (Russo et al., 2013) and decreased GABA in the medial prefrontal cortex as measured with proton magnetic resonance spectroscopy (MRS; Simpson et al., 2012). Moreover, similar to the potential efficacy of GABA-agonizing agents for addictions, recent animal models indicate that selective GABA release in the striatum may explain the efficacy of DBS for OCD (Burguiere et al., 2013; Xie et al., 2014).

\section{Glutamate}


Glutamatergic signaling is important for prefrontal top-down control over striatal dopamine (Arnsten et al., 2009). Converging evidence suggests aberrant frontostriatal glutamatergic signaling in OCD (Wu et al., 2012). Moreover, electrophysiological animal work indicates that the efficacy of ventral striatal DBS for OCD may depend on restored glutamatergic OFC control over striatal regions (McCracken et al., 2007; Yan et al., 2013), which might also explain the anti-compulsive effects of glutamatergic agents such as ketamine (Rodriguez et al., 2013). It was recently hypothesized that glutamatergic frontostriatal changes may also be critical for the transition of regular to compulsive drug use (van Huijstee and Mansvelder, 2015) and glutamatergic agents are promising interventions for the treatment of substance-use and gambling disorders (Pettorruso et al., 2014).

\section{Discussion}

We reviewed the symptomatic, neurocognitive, and neurotransmitter overlap of compulsivity in OCD, substance-use disorders and behavioral addictions, to determine the processes that are central to compulsivity. First, the available data suggest that compulsivity in OCD and addictions are related to impaired reward and punishment processing in the ventral striatum and associated attenuated dopamine release, and with negative reinforcement in limbic and anti-reward systems, which may at least partly explain the presence of repetitive selfdefeating behaviors. Second, compulsivity in OCD and addictions entails cognitive and behavioral inflexibility, which may be rooted in a shared impairment of ventromedial prefrontal top-down regulation, along with prefrontal serotonergic defects and excessive dopamine and glutamate signaling. Finally, habitual responding regardless of its consequences is an aspect of compulsivity that might be related to imbalances between ventral and dorsal frontostriatal recruitment. 
The Research Domain Criteria (RDoC) project does not cite compulsivity as one of its dimensional constructs or domains. However, features of compulsivity are grouped together within the $\mathrm{RDoC}$ positive valence system (i.e., reward processing and habits), and other aspects of compulsivity can be recognized within the negative valence and cognitive control domains. The current review suggests that compulsivity encompasses many of the RDoC constructs in a trans-diagnostic fashion with a shared dysregulation of frontostriatal circuits. The important question that remains to be answered in the future is whether compulsivity should be regarded one of the mono-dimensional building blocks of a new functional classification system or whether compulsivity can be better regarded as a combination of different one-dimensional constructs, which can be found in various DSM-5 diagnostic categories.

Apart from the reviewed similarities between compulsivity in OCD and addictions, there are also many differences that may have contributed to their classification in separate categories in DSM-5 (American Psychiatric Association, 2013; Potenza et al., 2009). In contrast, similarities between pathological gambling and substance addictions led to the re-classification of gambling and substance-use disorders in an addictions category in DSM-5 (American Psychiatric Association, 2013; Potenza et al., 2006; Petry, 2006). Among the many differences between OCD and addictions are pharmacological treatments for the disorders, with selective serotonin-reuptake inhibitors showing efficacy for OCD but not for addictions, and opioidreceptor antagonists showing efficacy for multiple addictions (Potenza et al., 2009) but generally not for OCD where opioid agonists rather than antagonists may have some efficacy (Goldsmith et al., 1999; Koran et al., 2005; Khazaal et al., 2006). However, certain OCD features like compulsivity may represent important trans-diagnostic domains that may be targeted in treatment efforts for both OCD and addictions. 
In pathological gambling, there has been reported high levels of (self-reported and behavioral) compulsivity that may be responsive to OCD-like interventions (Blanco et al., 20097), although this possibility warrants additional investigation. For further investigation of neurobiological features of compulsivity in OCD and addictive disorders, data-driven approaches and psychometric compulsivity measures may be particularly useful, for example using new compulsivity scales like the Dutch Dimensional Obsessive Compulsive Scale (DDOCS; in press) or the DSM-5 obsessive-compulsive spectrum scale (Le Beau et al, 2013). As an example of data-driven approaches, data-driven approaches may be particularly useful. For example, a factor structure derived from principal-components analysis assessing impulsivity-related measures in healthy and addicted individuals identified self-reported compulsivity as linking to measures of reward and punishment sensitivity (Meda et al., 2009). This factor grouping has been replicated in an independent college-gambling sample (Ginley et al., 2014) and linked to cocaine addiction (Hyatt et al., 2012), a familial history of alcoholism (Yarosh et al., 2014) and changes in drinking behaviors among college students (Dager et al., 2014). Importantly, this self-reported compulsivity factor has been linked to left insular/inferior-frontal-gyral activation during successful response inhibition (DeVito et al., 2013), blunted ventral-striatal activation and activation of the ventral tegmental area during reward processing (Andrews et al., 2011; Patel et al., 2013) and dorsal caudate reward activation differing in current versus remitted cocaine users (Hyatt et al., 2012). These findings support the notions that compulsivity and sensitivities to reward and punishment are associated and that these in turn are linked to neurobiological constructs implicated in addictions. Such studies should also be undertaken in OCD to determine if similar or distinct findings are observed. Another approach warranting consideration involves the identification of latent classes. Such an approach was recently used to define classes of 
obsessive-compulsive features that differed in quality and quantity and were linked to pathological gambling at diagnostic and genetic levels (Scherrer et al., 2015). The extent to which such latent classes relate to drug addictions warrants additional investigation.

Finally, compulsivity and its associated frontostriatal dysfunction appear to be common targets for neuromodulation in OCD, drug addiction, pathological gambling, binge-eating, and compulsive shopping (Protasio et al., 2015). For example, DBS of the ventral striatum is able to improve compulsivity in OCD via a reduction of frontostriatal overconnectivity (Figee et al., 2014) with similar changes suggested for DBS in addiction (Valencia-Alfonso et al., 2012). Likewise, cortical neuromodulation (e.g., rTMS of the medial prefrontal cortex) may change compulsivity in OCD and addiction through similar frontostriatal connectivity changes (Dunlop et al., 2015; de Ridder et al., 2011; Kravitz et al., 2015). Therefore, future studies of compulsivity and its neural correlates have great potential to advance neuromodulation for psychiatry.

Taken together, these findings suggest that trans-diagnostic measures of compulsivity warrant additional study in substance and behavioral addictions, as well as in OCD and other conditions (skin-picking, trichotillomania. binge-eating/obesity, compulsive shopping, compulsive sexual behaviors, problematic Internet use), with the hope that such studies may identify appropriate targets for prevention and treatment initiatives. 


\section{Role of Funding Sources}

This work was supported in part by the NIH (P20 DA027844), the Connecticut State Department of Mental Health and Addictions Services, and the Yale Gambling Center of Research Excellence grant from the National Center for Responsible Gaming. The NIH, the Connecticut State Department of Mental Health and Addictions Services, and the National Center for Responsible Gaming had no role in the content or writing of the manuscript or the decision to submit the paper for publication.

\section{Disclosures}

Dr. Potenza has received financial support or compensation for the following: has acted as consultant and/or advisor for Somaxon, Boehringer Ingelheim, Lundbeck, Ironwood, Shire, INSYS, and RiverMend Health; has received research support from the National Institutes of Health, Veterans Administration, Mohegan Sun Casino, the National Center for Responsible Gaming, Forest Laboratories, Ortho-McNeil, Oy-Contral Pharma/Biotie Therapies, GlaxoSmithKline, and Psyadon Pharmaceuticals; has participated in surveys, mailings or telephone consultations related to drug addiction, impulse control disorders, and other health topics; has consulted for law offices and the federal public defender's office on issues related to impulse control disorders; provides clinical care in the Connecticut Department of Mental Health and Addiction Services Problem Gambling Services Program; has performed grant reviews for the National Institutes of Health and other agencies; has acted as guest editor for journal sections and journals; has given academic lectures in grand rounds, CME events, and other clinical and scientific venues; and has generated books or book chapters for publishers of mental health texts. 


\section{Reference List}

Ahmari SE., Spellman T., Douglass NL., Kheirbek MA., Simpson HB., Deisseroth K., Gordon JA., Hen R., 2013. Repeated cortico-striatal stimulation generates persistent OCD-like behavior. Science 340:1234-1239.

Albelda N., Joel D., 2012. Animal models of obsessive-compulsive disorder: exploring pharmacology and neural substrates. Neurosci Biobehav Rev 36: $47-63$.

American Psychiatric Association, 2013. Diagnostic and statistical manual of mental disorders (5th ed.). Washington, DC

Andrews MA., Meda SA., Thomas AD., Potenza MN., Krystal JH., Worhunsky PD., Stevens MC., O’Malley SS., Book GA., Pearlson GD., 2011. Individuals Family History Positive for Alcoholism Show fMRI Abnormalities in Reward Sensitivity That Are Related to Impulsivity Factors. Biol Psychiatry 69:675683.

Balodis, I. M., Kober, H., Worhunsky, P. D., Stevens, M. C., Pearlson, G. D., Potenza, M.N., 2012. Diminished frontostriatal activity during processing of monetary rewards and losses in pathological gambling. Biological psychiatry, $71,749-57$.

Balodis, I. M., Kober, H., Worhunsky, P. D., White, M. a, Stevens, M. C., Pearlson, G. D., Sinha, R., et al., 2013. Monetary reward processing in obese individuals with and without binge eating disorder. Biological psychiatry, 73, 877-86. 
Balodis IM, Potenza MN, 2015. Anticipatory reward processing in addicted populations: a focus on the monetary incentive delay task. Biol Psychiatry 77:434-444.

Barlow, R.L., Alsiö, J., Jupp, B., Rabinovich, R., Shrestha, S., Roberts, A.C., Robbins, T.W., Dalley, J.W., 2015. Markers of Serotonergic Function in the Orbitofrontal Cortex and Dorsal Raphé Nucleus Predict Individual Variation in Spatial-Discrimination Serial Reversal Learning. Neuropsychopharmacology. 2015 Jan 8.

Bechara, A., Damasio, H., Damasio, A.R., 2000. Emotion, decision-making and the orbitofrontal cortex. Cereb. Cortex 10, 295-307.

Belin D., Everitt BJ., 2008. Cocaine seeking habits depend upon dopamine-dependent serial connectivity linking the ventral with the dorsal striatum. Neuron 57, $432-441$.

Berridge KC., 2007. The debate over dopamine's role in reward: the case for incentive salience. Psychopharmacology (Berl). 191, 391-431.

Blanco C., Potenza M.N., Kim S.W., Ibáñez A., Zaninelli R., Saiz-Ruiz J., Grant JE., 2009. A pilot study of impulsivity and compulsivity in pathological gambling. Psychiatry Res. 167, 161-8.

Boileau I. et al., 2014. In vivo evidence for greater amphetamine-induced dopamine release in pathological gambling: a positron emission tomography study with [(11)C]-(+)-PHNO. Mol Psychiatry 
Boog, M., Hoppener, P., Wetering BJ, V. D., Goudriaan, A. E., Boog, M. C., \& Franken, I. H., 2014. Cognitive Inflexibility in Gamblers is Primarily Present in Reward-Related Decision Making. Front Hum.Neurosci., 8, 569.

Bossong, M.G., Van Berckel, B,N., Boellaard, R., Zuurman, L., Schuit, R.C., Windhorst, A.D., Van Gerven, J.M., Ramsey, N.F., Lammertsma, A.A., Kahn, R.S., 2009. Delta 9-tetrahydrocannabinol induces dopamine release in the human striatum. Neuropsychopharmacology 34:759-66.

Brambilla F, Bellodi L, Perna G, Arancio C, Bertani A. Dopamine function in obsessive-compulsive disorder: growth hormone response to apomorphine stimulation. Biol Psychiatry. 1997 Nov 15;42(10):889-97.

Britton JC., Rauch SL., Rosso IM., Killgore WD., Price LM., Ragan J., Chosak A., Hezel DM., Pine DS, Leibenluft E, Pauls DL, Jenike MA, Stewart SE., 2010. Cognitive inflexibility and frontal-cortical activation in pediatric obsessivecompulsive disorder. J Am Acad Child Adolesc Psychiatry. 49, 944-53

Buhler M, Vollstadt-Klein S, Kobiella A, Budde H,Reed LJ, Braus DF, Buchel C, Smolka MN., 2009. Nicotine Dependence Is Characterized by Disordered Reward Processing in a Network Driving Motivation. Biol.Psychiatry, 67, $745-752$.

Burguiere, E., Monteiro, P., Feng, G., \& Graybiel, a. M., 2013. Optogenetic Stimulation of Lateral Orbitofronto-Striatal Pathway Suppresses Compulsive Behaviors. Science, 340, 1243-1246. 
Camilla d'Angelo LS, Eagle DM, Grant JE, Fineberg NA, Robbins TW, Chamberlain SR., 2014. Animal models of obsessive-compulsive spectrum disorders. CNS Spectr. 19, 28-49.

Casey BJ, Craddock N, Cuthbert BN, Hyman SE, Lee FS, Ressler KJ. DSM-5 and RDoC: progress in psychiatry research?, 2013. Nat Rev Neurosci., 14, 810-4.

Chamberlain SR, Fineberg NA, Blackwell AD, Robbins TW, Sahakian BJ., 2006. Motor inhibition and cognitive flexibility in obsessive-compulsive disorder and trichotillomania. Am J Psychiatry, 163, 1282-1284.

Chamberlain, S.R., Menzies, L., Hampshire, A., Suckling, J., Fineberg, N.A., del Campo, N., Aitken, M., Craig, K., Owen, A.M., Bullmore, E.T., Robbins, T.W., Sahakian, B.J., 2008. Orbitofrontal dysfunction in patients with obsessive-compulsive disorder and their unaffected relatives. Science 321, $421-422$.

Chen BT, Yau HJ, Hatch C, Kusumoto-Yoshida I, Cho SL, Hopf FW, Bonci A., 2013. Rescuing cocaine-induced prefrontal cortex hypoactivity prevents compulsive cocaine seeking. Nature 496, 359-362.

Choi JS, Shin YC, Jung WH, Jang JH, Kang DH, Choi CH, Choi SW, Lee JY, Hwang JY, Kwon JS., 2012. Altered brain activity during reward anticipation in pathological gambling and obsessive-compulsive disorder. PLoS One, 7, 9

Clarke, H.F., Dalley, J.W., Crofts, H.S., Robbins, T.W. \& Roberts, A.C., 2004. Cognitive inflexibility after prefrontal serotonin depletion. Science, 304, 878880. 
Clarke, H.F., Walker, S.C., Crofts, H.S., Dalley, J.W., Robbins, T.W. \& Roberts, A.C., 2005. Prefrontal serotonin depletion affects reversal learning but not attentional set shifting. Journal of Neuroscience, 25, 532-538.

Clarke, H.F., Walker, S.C., Dalley, J.W., Robbins, T.W. \& Roberts, A.C., 2007. Cognitive inflexibility after prefrontal serotonin depletion is behaviourally and neurochemically specific. Cerebral Cortex, 17, 18-27.

Clarke, H.F., Robbins, T.W. \& Roberts, A.C., 2008. Lesions of the medial striatum in monkeys produce perseverative impairments during reversal learning similar to those produced by lesions of the orbitofrontal cortex. Journal of Neuroscience, 28, 10972-10982

Clarke, H.F., Hill, G.J., Robbins, T.W. \& Roberts, A.C., 2011. Dopamine, but not serotonin, regulates reversal learning in the marmoset caudate nucleus. Journal of Neuroscience, 31, 4290-4297

Dager AD, Anderson BM, Rosen R, Khadka S, Sawyer B, Jiantonio-Kelly RE, Austad CS, Raskin SA, Tennen H, Wood RM, Fallahi CR, Pearlson GD., 2014. Functional magnetic resonance imaging (fMRI) response to alcohol pictures predicts subsequent transition to heavy drinking in college students. Addiction, 109, 585-595.

Daglish MRC, Williams TM, Wilson SJ, Taylor LG, Eap CB, Augsburger M, et al., 2008. Brain dopamine response in human opioid addiction. Br J Psychiatry J Ment Sci., 193, 65-72. 
Dalton GL, Ma LM, Phillips AG, Floresco SB., 2011. Blockade of NMDA GluN2B receptors selectively impairs behavioral flexibility but not initial discrimination learning. Psychopharmacology (Berl), 216: 525-535.

De Greck M, Enzi B, Prösch U, Gantman A, Tempelmann C, Northoff G, 2010. Decreased neuronal activity in reward circuitry of pathological gamblers during processing of personal relevant stimuli. Hum Brain Mapp, 31, 1802-12.

De Ridder D., Vanneste S., Kovacs S., Sunaert S., Dom G., 2011. Transient alcohol craving suppression by rTMS of dorsal anterior cingulate: an fMRI and LORETA EEG study. Neurosci. Lett., 496, 5-10

Denys D, van der Wee N, Janssen J, de Geus F, Westenberg HG, 2004. Low level of dopaminergic D2 receptor binding in obsessive-compulsive disorder. Biol Psychiatry 55, 1041-1045.

Denys D. Obsessionality \& compulsivity: a phenomenology of obsessive-compulsive disorder. Philos Ethics Humanit Med., 6, 3 (2011).

Denys D, de Vries F, Cath D, Figee M, Vulink N, Veltman DJ, van der Doef TF, Boellaard R, Westenberg H, van Balkom A, Lammertsma AA, van Berckel BN., 2013. Dopaminergic activity in Tourette syndrome and obsessivecompulsive disorder. Eur Neuropsychopharmacol., 23, 1423-31.

Derbyshire, K. L., Chamberlain, S. R., Odlaug, B. L., Schreiber, L. R., \& Grant, J. E., 2014. Neurocognitive functioning in compulsive buying disorder. Annals of Clinical Psychiatry, 26, 57-63. 
Deroche-Gamonet V, Belin D, Piazza PV., 2004. Evidence for addiction-like behavior in the rat. Science 305:1014-1017.

de Ruiter, M.B., Veltman, D. J., Goudriaan, A. E., Oosterlaan, J., Sjoerds, Z., \& van den Brink, W., 2009. Response perseveration and ventral prefrontal sensitivity to reward and punishment in male problem gamblers and smokers. Neuropsychopharmacology, 34, 1027-1038.

DeVito EE, Meda SA, Jiantonio R, Potenza MN, Krystal JH, Pearlson GD., 2013. Neural correlates of impulsivity in healthy males and females with family histories of alcoholism.Neuropsychopharmacology, 38, 1854-63.

De Weijer BA, van de Giessen E, van Amelsvoort TA, Boot E, Braak B, Janssen IM, van de Laar A, Fliers E, Serlie MJ, Booij J., 2011. Lower striatal dopamine D2/3 receptor availability in obese compared with non-obese subjects. EJNMMI Res., 16, 37.

Diekhof EK., Falkai P., Gruber O., 2008. Functional neuroimaging of reward processing and decision-making: a review of aberrant motivational and affective processing in addiction and mood disorders. Brain Res.Rev., 59, 164184.

Dunlop K. Woodside B. Olmsted M. Colton P. Giacobbe P. Downar J. Reductions in cortico-striatal hyperconnectivity accompany successful treatment of obsessive-compulsive disorder with dorsomedial prefrontal rTMS. Biological Psychiatry. Conference: 70th Annual Scientific Convention and Meeting of the Society of Biological Psychiatry, 77 (9 SUPPL. 1) (pp 234S), 2015. 
Enoch M-A. The Influence of Gene-Environment Interactions on the Development of Alcoholism and Drug Dependence. Curr Psychiatry Rep. 2012 Apr $1 ; 14(2): 150-8$.

Ersche KD, Roiser JP, Robbins TW, Sahakian BJ. Chronic cocaine but not chronic amphetamine use is associated with perseverative responding in humans. Psychopharmacology (Berl). 2008 Apr;197(3):421-31.

Ersche KD, Roiser JP, Abbott S, Craig KJ, Müller U, Suckling J, Ooi C, Shabbir SS, Clark L, Sahakian BJ, Fineberg NA, Merlo-Pich EV, Robbins TW, Bullmore ET. Response perseveration in stimulant dependence is associated with striatal dysfunction and can be ameliorated by a $\mathrm{D}(2 / 3)$ receptor agonist. Biol Psychiatry. 2011 Oct 15;70(8):754-62

Everitt BJ, Robbins TW: Neural systems of reinforcement for drug addiction: from actions to habits to compulsion. Nat Neurosci 2005; 8:1481-1489

Everitt BJ, Belin D, Economidou D, Pelloux Y, Dalley JW, Robbins TW. Review. Neural mechanisms underlying the vulnerability to develop compulsive drugseeking habits and addiction. Philos Trans R Soc Lond B Biol Sci. 2008 Oct 12;363(1507):3125-35.

Everitt BJ, Robbins TW. From the ventral to the dorsal striatum: devolving views of their roles in drug addiction. Neurosci Biobehav Rev. 2013 Nov;37(9 Pt A): $1946-54$.

Figee M, Booij J, Denys D. Molecular imaging of Obsessive compulsive disorder in: Shenton M E., Turetsky B I., editors. Understandig Neuropsychiatric 
Disorders: Insights from Neuroimaging. S.1.: Cambridge University Press; 2010

Figee M, Vink M, de Geus F, Vulink N, Veltman DJ, Westenberg H, Denys D, Dysfunctional Reward Circuitry in Obsessive-Compulsive Disorder. Biological Psychiatry 2011;69(9):867-874

Figee M, Wielaard I, Mazaheri A, Denys D. Neurosurgical targets for compulsivity: what can we learn from acquired brain lesions? Neurosci Biobehav Rev. 2013 Mar;37(3):328-39 .

Figee M, Luigjes J, Smolders R, Valencia-Alfonso CE, van Wingen G, de Kwaasteniet B, Mantione M, Ooms P, de Koning P, Vulink N, Levar N, Droge L, van den Munckhof P, Schuurman PR, Nederveen A, van den Brink W, Mazaheri A, Vink M, Denys D. Deep brain stimulation restores frontostriatal network activity in obsessive-compulsive disorder. Nature Neuroscience 2014 Aug 26;17(9):1286.

Filip M, Frankowska M, Sadakierska-Chudy A, Suder A, Szumiec L, Mierzejewski P, Bienkowski P, Przegaliński E, Cryan JF. GABA-B receptors as a therapeutic strategy in substance use disorders: Focus on positive allosteric modulators. Neuropharmacology. 2015 Jan;88C:36-47.

Fineberg NA, Chamberlain SR, Goudriaan AE, Stein DJ, Vanderschuren LJMJ, Gillan CM, et al. New developments in human neurocognition: clinical, genetic, and brain imaging correlates of impulsivity and compulsivity. CNS Spectr. 2014 Feb;19(1):69-89. 
Fineberg NA, Chamberlain SR, Hollander E, Boulougouris V, Robbins TW (2011) Translational approaches to obsessive-compulsive disorder: from animal models to clinical treatment. Br J Pharmacol 164:1044-1061

Fineberg NA, Brown A, Reghunandanan S, Pampaloni I (2012) Evidence-based pharmacotherapy of obsessive-compulsive disorder. Int J Neuropsychopharmacol 15:1173-1191.

Flaisher-Grinberg S, Klavir O, Joel D (2008) The role of 5-HT2A and 5-HT2C receptors in the signal attenuation rat model of obsessive-compulsive disorder. Int J Neuropsychopharmacol 11: 811-825.

Floresco SB, Zhang Y, Enomoto T (2009) Neural circuits subserving behavioral flexibility and their relevance to schizophrenia. Behav Brain Res 204: 396409.

Freyer T, Klöppel S, Tüscher O, Kordon A, Zurowski B, Kuelz AK, Speck O, Glauche V, Voderholzer U. Frontostriatal activation in patients with obsessive-compulsive disorder before and after cognitive behavioral therapy. Psychol Med. 2011 Jan;41(1):207-16.

Gastambide F, Cotel MC, Gilmour G, O'Neill MJ, Robbins TW, Tricklebank MD (2012) Selective remediation of reversal learning deficits in the neurodevelopmental MAM model of schizophrenia by a novel mGlu5 positive allosteric modulator. Neuropsychopharmacology 37: 1057-1066.

Gillan CM, Morein-Zamir S, Urcelay GP, Sule A, Voon V, Apergis-Schoute AM, Fineberg NA, Sahakian BJ, Robbins TW. Enhanced avoidance habits in obsessive-compulsive disorder. Biol Psychiatry. 2014 Apr 15;75(8):631-8. 
Gillan CM, Apergis-Schoute AM, Morein-Zamir S, Urcelay GP, Sule A, Fineberg NA, Sahakian BJ, Robbins TW. Functional neuroimaging of avoidance habits in obsessive-compulsive disorder. Am J Psychiatry. 2015 Mar 1;172(3):28493.

Ginley MK, Whelan JP, Meyers AW, Relyea GE, Pearlson GD. Exploring a multidimensional approach to impulsivity in predicting college student gambling. J Gambl Stud. 2014 Jun;30(2):521-36.

Goldsmith TB, Shapira NA, Keck PE Jr. Rapid remission of OCD with tramadol hydrochloride. Am J Psychiatry. 1999 Apr;156(4):660-1.

Goodman A. Neurobiology of addiction. An integrative review. Biochem Pharmacol. 2008 Jan 1;75(1):266-322.

Goudriaan, A. E., Oosterlaan, J., de Beurs, E., \& van den Brink, W. (2006). Neurocognitive functions in pathological gambling: a comparison with alcohol dependence, Tourette syndrome and normal controls. Addiction, 101, 534547.

Goudriaan AE, de Ruiter MB, van den Brink W, Oosterlaan J, Veltman DJ. Brain activation patterns associated with cue reactivity and craving in abstinent problem gamblers, heavy smokers and healthy controls: an fMRI study. Addict Biol. 2010 Oct;15(4):491-503

Hamilton KR, Ansell EB, Reynolds B, Potenza MN, Sinha R (2013) Self-reported impulsivity, but not behavioral choice or response impulsivity, partially mediates the effect of stress on drinking behavior. Stress 16:3-15. 
Hampshire A, Owen AM (2006). Fractionating attentional control using event-related fMRI. Cereb Cortex 16: 1679-1689.

HarrisonBJ,Soriano-MasC,PujolJ,etal. Altered corticostriatal functional connectivity in obsessive-compulsive disorder. Arch Gen Psychiatry. 2009;66(11):11891200.

Harrison BJ, Pujol J, Cardoner N, Deus J, Alonso P, López-Solà M, ContrerasRodríguez O, Real E, Segalàs C, Blanco-Hinojo L, Menchon JM, Soriano-Mas C. Brain corticostriatal systems and the major clinical symptom dimensions of obsessive-compulsive disorder. Biol Psychiatry. 2013 Feb 15;73(4):321-8.

Heilig M, Thorsell A, Sommer WH, Hansson AC, Ramchandani VA, George DT, et al. Translating the neuroscience of alcoholism into clinical treatments: from blocking the buzz to curing the blues. Neurosci Biobehav Rev. 2010 Nov;35(2):334-44.

Hollander E, Pallanti S, Baldini Rossi N, Sood E, Baker BR, Buchsbaum MS (2005). Imaging monetary reward in pathological gamblers. World J Biol Psychiatry. 6, 113-120.

Hommer D.W., Bjork, J.M., Gilman J.M. (2011). Imaging brain response to reward in addictive disorders. Ann. N.Y. Acad. Sci. 1216, 50-61.

Honsi, A., Mentzoni, R. A., Molde, H., \& Pallesen, S. (2013). Attentional bias in problem gambling: a systematic review. Journal of Gambling Studies, 29, 359375. 
Hyatt CJ, Assaf M, Muska C, Rosen RI, Thomas AD, Potenza MN, Johnson MR, Hylton JL, Andrews MM, Reynolds B, Krystal JH, Pearlson GD (2012) Reward-Related Dorsal Striatal Activity Differences Between Former and Current Cocaine Dependent Subjects during an Interactive Competitive Game. PLoS One 7(5):e34917.

Insel T, Cuthbert B, Garvey M, Heinssen R, Pine DS, Quinn K, Sanislow C, Wang P. Research domain criteria (RDoC): toward a new classification framework for research on mental disorders. Am J Psychiatry. 2010 Jul;167(7):748-51.

Izquierdo A, Jentsch JD. Reversal learning as a measure of impulsive and compulsive behavior in addictions. Psychopharmacology (Berl). 2012 Jan;219(2):607-20.

Joel D, Avisar A (2001) Excessive lever pressing following post-training signal attenuation in rats: a possible animal model of obsessive compulsive disorder? Behav Brain Res 123: 77-87.

Joel D, Doljansky J (2003) Selective alleviation of compulsive lever-pressing in rats by D1, but not D2, blockade: possible implications for the involvement of D1 receptors in obsessive-compulsive disorder. Neuropsychopharmacology 28:77-85.

Joel D, Ben-Amir E, Doljansky J, Flaisher S (2004) ‘Compulsive’ lever-pressing in rats is attenuated by the serotonin re-uptake inhibitors paroxetine and fluvoxamine but not by the tricyclic antidepressant desipramine or the anxiolytic diazepam. Behav Pharmacol 15: 241-252. 
Jonkman S, Pelloux Y, Everitt BJ (2012) Drug intake is sufficient, but conditioning is not necessary for the emergence of compulsive cocaine seeking after extended self-administration. Neuropsychopharmacology 37:1612-1619.

Jung, W. H., Kang, D.-H., Han, J. Y., Jang, J. H., Gu, B.-M., Choi, J.-S., Jung, M. H., et al. (2011).Aberrant ventral striatal responses during incentive processing in unmedicated patients with obsessive-compulsive disorder. Acta psychiatrica Scandinavica, 123(5), 376-86.

Kasanetz F, Deroche-Gamonet V, Berson N, Balado E, Lafourcade M, Manzoni O, Piazza PV (2010) Transition to addiction is associated with a persistent impairment in synaptic plasticity. Science 328:1709-1712.

Kaufmann C, Beucke JC, Preuße F, Endrass T, Schlagenhauf F, Heinz A, Juckel G, Kathmann N. Medial prefrontal brain activation to anticipated reward and loss in obsessive-compulsive disorder. Neuroimage Clin. 2013 Jan 17;2:212-20.

Kashyap H, Fontenelle LF, Miguel EC, Ferrão YA, Torres AR, Shavitt RG, FerreiraGarcia R, Rosário D, C M, \& Yücel M (2012). ‘Impulsive compulsivity’ in obsessive-compulsive disorder: A phenotypic marker of patients with poor clinical outcome, Journal of Psychiatric Research 46, 1146-1152.

Kennett J, Matthews S, \& Snoek A (2013). Pleasure and Addiction, Frontiers in Psychiatry 4

Khazaal Y, Krenz S, Benmebarek M, Zullino DF. Worsening of obsessivecompulsive symptoms under methadone tapering. Prog Neuropsychopharmacol Biol Psychiatry. 2006 Sep 30;30(7):1350-2. 
Koran LM, Aboujaoude E, Bullock KD, Franz B, Gamel N, Elliott M. Double-blind treatment with oral morphine in treatment-resistant obsessive-compulsive disorder. J Clin Psychiatry. 2005 Mar;66(3):353-9.

Koob GF (2015). The dark side of emotion: The addiction perspective, European Journal of Pharmacology, in press.

Koob GF, Le Moal M. Plasticity of reward neurocircuitry and the "dark side" of drug addiction. Nat Neurosci. 2005 Nov;8(11):1442-4.

Koob GF, Volkow ND. Neurocircuitry of addiction. Neuropsychopharmacol Off Publ Am Coll Neuropsychopharmacol. 2010 Jan;35(1):217-38.

Kravitz AV, Tomasi D, LeBlanc KH, Baler R, Volkow ND, Bonci A, Ferré S. Cortico-striatal circuits: Novel therapeutic targets for substance use disorders. Brain Res. 2015 Apr 9.

Krishnan-Sarin S, Reynolds B, Duhig AM, Smith A, Liss T, McFetridge A, Cavallo DA, Carroll KM, Potenza MN (2007) Behavioral impulsivity predicts treatment outcome in a smoking cessation program for adolescent smokers. Drug Alc Depend 88:79-82

Kühn S, Gallinat J. Common biology of craving across legal and illegal drugs - a quantitative meta-analysis of cue-reactivity brain response. (2011) Eur J Neurosci. 33(7):1318-26

RT LeBeau, ER Mischel, HB Simpson, D Mataix-Cols, KA Phillips. Preliminary assessment of obsessive-compulsive spectrum disorder scales for DSM-5 
Journal of Obsessive-Compulsive and Related Disorders 2 (2), 114-118

Leeman, R. F. \& Potenza, M. N. (2012). Similarities and differences between pathological gambling and substance use disorders: a focus on impulsivity and compulsivity. Psychopharmacology (Berlin), 219, 469-490.

Limpens JH, Damsteegt R, Broekhoven MH, Voorn P, Vanderschuren LJ (2014) Pharmacological inactivation of the prelimbic cortex emulates compulsive reward seeking in rats. Brain research.

Martinez D, Saccone PA, Liu F, Slifstein M, Orlowska D, Grassetti A, et al. Deficits in dopamine $\mathrm{D}(2)$ receptors and presynaptic dopamine in heroin dependence: commonalities and differences with other types of addiction. Biol Psychiatry. 2012 Feb 1;71(3):192-8.

Martin-Soelch C, Missimer J, Leenders KL, Schultz W (2003). Neural activity related to the processing of increasing monetary reward in smokers and non-smokers. Eur.J.Neurosci. 18, 680-688.

McCracken CB, Grace AA (2007), High-frequency deep brain stimulation of the nucleus accumbens region suppresses neuronal activity and selectively modulates afferent drive in rat orbitofrontal cortex in vivo. $\mathrm{J}$ Neurosci,27:12601-12610. 7.

Meda SA, Stevens MC, Potenza MN, Pittman B, Gueorguieva R, Andrews MA, Thomas AD, Muska C, Hylton JL, Pearlson GD (2009) Investigating the behavioral constructs of impulsivity domains using principal component analysis. Behav Pharmacol 20:390-399. 
Menzies, L., Achard, S., Chamberlain, S.R., Fineberg, N.A., Chen, C.-H., del Campo, N., Sahakian, B.J., Robbins, T.W., Bullmore, E.T., 2007. Neurocognitive endophenotypes of obsessive-compulsive disorder. Brain 13 e-pub ahead of print, September.

Meunier D, Ersche KD, Craig KJ, Fornito A, Merlo-Pich E, Fineberg NA, et al. Brain functional connectivity in stimulant drug dependence and obsessivecompulsive disorder. NeuroImage. 2012 Jan 16;59(2):1461-8.

Müller CP, Homberg JR. The role of serotonin in drug use and addiction. Behav Brain Res. 2015 Jan 15;277:146-92.

Naqvi NH, Rudrauf D, Damasio H, Bechara A. Damage to the insula disrupts addiction to cigarette smoking. Science. 2007 Jan 26; 315(5811):531-4.

Nuttin B, Gielen F, van Kuyck K, Wu H, Luyten L, Welkenhuysen M, Brionne TC, Gabriëls L. Targeting bed nucleus of the stria terminalis for severe obsessivecompulsive disorder: more unexpected lead placement in obsessivecompulsive disorder than in surgery for movement disorders. World Neurosurg. 2013 Sep-Oct;80(3-4):S30.e11-6.

Odlaug, B. L., Chamberlain, S. R., Kim, S. W., Schreiber, L. R., \& Grant, J. E. (2011). A neurocognitive comparison of cognitive flexibility and response inhibition in gamblers with varying degrees of clinical severity. Psychol.Med., 41, 2111-2119.

Olver JS, O’ Doherty G, Jones GR, Burrows GD, Tochon-Danguy HJ, Ackermann U, Scott A, Norman TR (2009). Dopamine D1 receptor binding in the striatum of patients with obsessive-compulsive disorder. J Affect Disord., 114, 321-6. 
Ornstein, T.J., Iddon, J.L., Baldacchino, A.M., Sahakian, B.J., London, M., Everitt, B.J. \& Robbins, T.W. (2000) Profiles of cognitive dysfunction in chronic amphetamine and heroin abusers. Neuropsychopharmacology, 23, 113-126.

Patel KT, Stevens MC, Meda SA, Muska C, Thomas AD, Potenza MN, Pearlson GD (2013) Robust Changes in Reward Circuitry during Reward Loss in Current and Former Cocaine Users during Performance of a Monetary Incentive Delay Task. Biol Psychiatry 72:529-537.

Pettorruso M, De Risio L, Martinotti G, Di Nicola M, Ruggeri F, Conte G, Di Giannantonio M, Janiri L. Targeting the glutamatergic system to treat pathological gambling: current evidence and future perspectives. Biomed Res Int. $2014 ; 2014: 109786$.

Pitchot W, Hansenne M, Moreno AG, Ansseau M. Growth hormone response to apomorphine in obsessive-compulsive disorder. J Psychiatry Neurosci. 1996 Nov;21(5):343-5.

Potenza MN, Steinberg MA, Skudlarski P, Fulbright RK, Lacadie CM, Wilber MK, Rounsaville BJ, Gore JC, Wexler BE (2003) Gambling urges in pathological gamblers: An fMRI study. Arch Gen Psychiatry 60: 828-836.

Potenza MN (2006) Should Addictive Disorders Include Non-Substance-Related Conditions? Addiction 101(s1):142-151.

Potenza MN, Koran LM, Pallanti S (2009) The relationship between obsessivecompulsive and impulse control disorders: A current understanding and future research directions. Psychiatry Res 170:22-31. 
Pelloux Y, Everitt BJ, Dickinson A (2007) Compulsive drug seeking by rats under punishment: effects of drug taking history. Psychopharmacology 194:127-137.

Pelloux Y, Murray JE, Everitt BJ (2013) Differential roles of the prefrontal cortical subregions and basolateral amygdala in compulsive cocaine seeking and relapse after voluntary abstinence in rats. The European journal of neuroscience.

Pelloux Y, Dilleen R, Economidou D, Theobald D, Everitt BJ (2012) Reduced forebrain serotonin transmission is causally involved in the development of compulsive cocaine seeking in rats. Neuropsychopharmacology 37:25052514.

Perani D, Garibotto V, Gorini A, Moresco RM, Henin M, Panzacchi A, Matarrese M, Carpinelli A, Bellodi L, Fazio F (2008). In vivo PET study of 5HT(2a) serotonin and $\mathrm{D}(2)$ dopamine dysfunction in drug-naïve obsessive-compulsive disorder. Neuroimage, 42, 306-14.

Peters J, Kalivas PW, Quirk GJ. Extinction circuits for fear and addiction overlap in prefrontal cortex. Learn Mem. 2009 Apr 20;16(5):279-88.

Petry NM. Addiction. 2006 Sep;101 Suppl 1:152-60. Should the scope of addictive behaviors be broadened to include pathological gambling?

Protasio MI, da Silva JP, Arias-Carrion O, Nardi AE, Machado S, Cruz MS. Repetitive transcranial magnetic stimulation to treat substance use disorders and compulsive behavior. CNS Neurol Disord Drug Targets. 2015;14(3):33140. 
Rachman S, de Silva P, Roper G (1976) The spontaneous decay of compulsive urges. Behaviour research and therapy. 14: 445-453

Radua J, van den Heuvel OA, Surguladze S, Mataix-Cols D. Meta-analytical comparison of voxel-based morphometry studies in obsessive-compulsive disorder vs other anxiety disorders. Arch Gen Psychiatry. 2010 Jul;67(7):70111.

Remijnse PL, Nielen MM, van Balkom AJ, Cath DC, van OP, Uylings HB, Veltman DJ. (2006).Reduced orbitofrontal-striatal activity on a reversal learning task in obsessive-compulsive disorder. Arch.Gen.Psychiatry 63[11], 1225-1236.

Reuter J, Raedler T, Rose M, Hand I, Gläscher J, Büchel C (2005). Pathological gambling is linked to reduced activation of the mesolimbic reward system. Nat Neurosci. 8, 147-8.

Robbins TW, Gillan CM, Smith DG, Wit SD, Ersche KD (2011). Neurocognitive endophenotypes of impulsivity and compulsivity: towards dimensional psychiatry. Trends in Cognitive Sciences (2011), 1-11

Robinson TE, Berridge KC. The incentive sensitization theory of addiction: some current issues. Philos Trans R Soc B Biol Sci. 2008 Oct 12;363(1507):313746.

Rodriguez CI, Kegeles LS, Levinson A, Feng T, Marcus SM, Vermes D, Flood P, Simpson HB. Randomized controlled crossover trial of ketamine in obsessivecompulsive disorder: proof-of-concept. Neuropsychopharmacology. 2013 Nov;38(12):2475-83. 
Rotge, J., Guehl, D., Dilharreguy, B., Cuny, E., Tignol, J., Bioulac, B., Allard, M., et al. (2008). Provocation of obsessive-compulsive symptoms: a quantitative voxel-based meta-analysis of functional neuroimaging studies. Journal of Psychiatry \& Neuroscience 33, 405-412.

Rothkirch M, Schmack K, Schlagenhauf F, Sterzer P. Implicit motivational value and salience are processed in distinct areas of orbitofrontal cortex. NeuroImage. 2012 Sep;62(3):1717-25.

Russo AJ, Pietsch SC. Biomark Insights. (2013) Decreased Hepatocyte Growth Factor (HGF) and Gamma Aminobutyric Acid (GABA) in Individuals with Obsessive-Compulsive Disorder (OCD). Biomark Insights, 8, 107-14.

Sakai Y, Narumoto J, Nishida S, et al. Corticostriatal functional connectivity in nonmedicated patients with obsessive-compulsive disorder. Eur Psychiatry. 2011;26(7):463-469.

Sanavio E (1988). Obsessions and compulsions: the Padua Inventory. Behav Res Ther 26:169-177.

Schmitz, F., Naumann, E., Trentowska, M., \& Svaldi, J. (2014). Attentional bias for food cues in binge eating disorder. Appetite, 80, 70-80.

Scherrer JF, Xian H, Slutske WS, Eisen SA, Potenza MN. Associations Between Obsessive-Compulsive Classes and Pathological Gambling in a National Cohort of Male Twins. JAMA Psychiatry. 2015 Feb 11.

Schultz W (1998). Predictive reward signal of dopamine neurons. J Neurophysiol. 80, 1-27. 
Schultz W, Tremblay L, Hollerman JR. Reward processing in primate orbitofrontal cortex and basal ganglia. Cerebr Cortex (2000) 10, 272-283.

Sesia T, Bizup B, Grace AA. Evaluation of animal models of obsessive-compulsive disorder: correlation with phasic dopamine neuron activity. Int $\mathbf{J}$ Neuropsychopharmacol. 2013 Jul;16(6):1295-307.

Simpson HB, Shungu DC, Bender J Jr, Mao X, Xu X, Slifstein M, Kegeles LS. (2012) Investigation of cortical glutamate-glutamine and $\gamma$-aminobutyric acid in obsessive-compulsive disorder by proton magnetic resonance spectroscopy. Neuropsychopharmacology, 37(12), 2684-92.

Sjoerds, Z., de Wit, S., van den Brink, W., Beekman, A. J., Penninx, B. W. J. H., \& Veltman, D. J. (2013). Behavioral and neuroimaging evidence for overreliance on habit learning in alcohol-dependent patients. Translational Psychiatry, 3:e337.

Stalnaker TA, Takahashi Y, Roesch MR, Schoenbaum G. Neural Substrates of Cognitive Inflexibility after Chronic Cocaine Exposure. Neuropharmacology. 2009;56(Suppl 1):63-72.

Stice E, Yokum S, Bohon C, Marti N, Smolen A (2010). Reward circuitry responsivity to food predicts future increases in body mass: Moderating effects of DRD2 and DRD4. Neuroimage 50, 1618-1625.

Szechtman H., Sulis W., Eilam D (1998) Quinpirole induces compulsive checking behavior in rats: a potential animal model of obsessive-compulsive disorder (OCD) Behav Neurosci 112:1475-1485. 
Tavares H., Gentil V. Pathological gambling and obsessive-compulsive disorder: towards a spectrum of disorders of volition. Rev Bras Psiquiatr 2007; 29: 10717.

Upadhyay, J., Maleki, N., Potter, J., Elman, I., Rudrauf, D., Knudsen, J., Wallin, D., et al. (2010). Alterations in brain structure and functional connectivity in prescription opioid-dependent patients. Brain 133, 2098-114.

Valencia-Alfonso CE, Luigjes J, Smolders R, Cohen MX, Levar N, Mazaheri A, van den Munckhof P, Schuurman PR, van den Brink W, Denys D. Effective deep brain stimulation in heroin addiction: a case report with complementary intracranial electroencephalogram. Biol Psychiatry. 2012 Apr 15;71(8):e35-7

Vanderschuren LJ, Everitt BJ. Drug seeking becomes compulsive after prolonged cocaine self-administration. Science. 2004 Aug 13;305(5686):1017-9.

Van Hell HH, Vink M, Ossewaarde L, Jager G, Kahn RS, Ramsey NF. Chronic effects of cannabis use on the human reward system: an fMRI study. Eur Neuropsychopharmacol. 2010 Mar;20(3):153-63.

Van Holst RJ, van den Brink W, Veltman DJ, Goudriaan AE. Why gamblers fail to win: a review of cognitive and neuroimaging findings in pathological gambling. Neurosci Biobehav Rev. 2010 Jan;34(1):87-107.

Van Holst RJ, Schilt T. Drug-related decrease in neuropsychological functions of abstinent drug users. Curr Drug Abuse Rev. 2011 Mar;4(1):42-56.

Van Holst, R. J., Lemmens, J. S., Valkenburg, P. M., Peter, J., Veltman, D. J., \& Goudriaan, A. E. (2012). Attentional bias and disinhibition toward gaming 
cues are related to problem gaming in male adolescents. J.Adolesc.Health, 50, 541-546.

van Holst RJ, Veltman DJ, Büchel C, van den Brink W, Goudriaan AE. Distorted expectancy coding in problem gambling: is the addictive in the anticipation? Biol Psychiatry. 2012 Apr 15;71(8):741-8.

Van Huijstee AN, Mansvelder HD.Glutamatergic synaptic plasticity in the mesocorticolimbic system in addiction. Front Cell Neurosci. 2015 Jan $20 ; 8: 466$.

Van de Giessen E, Celik F, Schweitzer DH, van den Brink W, Booij J. Dopamine D2/3 receptor availability and amphetamine-induced dopamine release in obesity. J Psychopharmacol. 2014 Sep;28(9):866-73.

Vanes LD, van Holst RJ, Jansen JM, van den Brink W, Oosterlaan J, Goudriaan AE. Contingency Learning in Alcohol Dependence and Pathological Gambling: Learning and Unlearning Reward Contingencies. Alcohol Clin Exp Res. 2014 Jun;38(6):1602-10.

Vlachou S, Markou A.GABAB receptors in reward processes. Adv Pharmacol. 2010;58:315-71

Vollstädt-Klein S, Wichert S, Rabinstein J, Bühler M, Klein O, Ende G, et al. Initial, habitual and compulsive alcohol use is characterized by a shift of cue processing from ventral to dorsal striatum. Addict Abingdon Engl. 2010 Oct;105(10):1741-9. 
Volkow ND, Ding YS, Fowler JS, Wang GJ, Logan J, Gatley JS, et al. Is methylphenidate like cocaine? Studies on their pharmacokinetics and distribution in the human brain. Arch Gen Psychiatry. 1995 Jun;52(6):456-63.

Volkow ND, Wang GJ, Fowler JS, Logan J, Gatley SJ, Hitzemann R, Chen AD, Dewey SL, Pappas N. Decreased striatal dopaminergic responsiveness in detoxified cocaine-dependent subjects. Nature. 1997; 386(6627):830-3.

Volkow, N.D., Fowler, J.S., 2000. Addiction, a disease of compulsion and drive: involvement of the orbitofrontal cortex. Cereb. Cortex 10, 318-325.

Volkow ND, Wang GJ, Telang F, Fowler JS, Thanos PK, Logan J, Alexoff D, Ding YS, Wong C, Ma Y, Pradhan K. Low dopamine striatal D2 receptors are associated with prefrontal metabolism in obese subjects: possible contributing factors. Neuroimage. 2008 Oct 1;42(4):1537-43

Volkow ND, Wang G-J, Fowler JS, Tomasi D, Telang F. Addiction: Beyond dopamine reward circuitry. Proc Natl Acad Sci. 2011 Sep 13;108(37):1503742.

Volkow ND, Wang G-J, Fowler JS, Tomasi D. Addiction Circuitry in the Human Brain. Annu Rev Pharmacol Toxicol. 2012 Feb 10;52:321-36.

Voon, V., Derbyshire, K., Ruck, C., Irvine, M. A., Worbe, Y., Enander, J. et al. (2014). Disorders of compulsivity: a common bias towards learning habits. Mol.Psychiatry.

Walitza S, Marinova Z, Grünblatt E, Lazic SE, Remschmidt H, Vloet TD, Wendland JR. Trio study and meta-analysis support the association of genetic variation at 
the serotonin transporter with early-onset obsessive-compulsive disorder. Neurosci Lett. 2014 Sep 19;580:100-3.

Wang GJ, Volkow ND, Logan J, Pappas NR, Wong CT, Zhu W, Netusil N, Fowler JS. Brain dopamine and obesity. Lancet. 2001 Feb 3;357(9253):354-7.

Watkins LH, Sahakian BJ, Robertson MM, Veale DM, Rogers RD, Pickard KM et al (2005). Executive function in Tourette's syndrome and obsessive-compulsive disorder. Psychol Med 35:571-582.

Welkenhuysen M, Gligorijevic I, Ameye L, Prodanov D, Van Huffel S, Nuttin B. Neuronal activity in the bed nucleus of the stria terminalis in a rat model for obsessive-compulsive disorder. Behav Brain Res. 2013 Mar 1;240:52-9.

Whiteside SP, Port JD, Abramowitz JS. A meta-analysis of functional neuroimaging in obsessive-compulsive disorder. Psychiatry Res. 2004 Nov 15;132(1):69-79.

Woicik PA, Urban C, Alia-Klein N, Henry A, Maloney T, Telang F, Wang GJ, Volkow ND, Goldstein RZ. A pattern of perseveration in cocaine addiction may reveal neurocognitive processes implicit in the Wisconsin Card Sorting Test. Neuropsychologia. 2011 Jun;49(7):1660-9.

Wrase J, Schlagenhauf F, Kienast T, Wüstenberg T, Bermpohl F, Kahnt T, Beck A, Ströhle A, Juckel G, Knutson B, Heinz A. Dysfunction of reward processing correlates with alcohol craving in detoxified alcoholics. Neuroimage. 2007 Apr 1;35(2):787-94. 
Willuhn, I., Burgeno, L.M., Everitt, B.J. \& Phillips, P.E.M. Hierarchical recruitment of phasic dopamine signaling in the striatum during the progression of cocaine use. Proc. Natl. Acad. Sci. USA 109, 20703-20708 (2012).

Wu K, Hanna GL, Rosenberg DR, Arnold PD (2012). The role of glutamate signaling in the pathogenesis and treatment of obsessive-compulsive disorder. Pharmacol Biochem Behav, 100(4):726-35.

Xie Y, Heida T, Stegenga J, Zhao Y, Moser A, Tronnier V, Feuerstein TJ, Hofmann UG. (2014) High-frequency electrical stimulation suppresses cholinergic accumbens interneurons in acute rat brain slices through GABAB receptors. European Journal of Neuroscience, Sep 23.

Xue Y, Steketee JD, Sun W (2012) Inactivation of the central nucleus of the amygdala reduces the effect of punishment on cocaine self-administration in rats. The European Journal of Neuroscience 35:775-783.

Yan N, Chen N, Zhu H, Zhang J, Sim M, Ma Y, Wang W (2013) High-frequency stimulation of nucleus accumbens changes in dopaminergic reward circuit. PLoS One, 8(11):e79318.

Yarosh HL, Hyatt CJ, Meda SA, Jiantonio-Kelly R, Potenza MN, Assaf M, Pearlson G., 2014. Relationships between reward sensitivity, risk-taking and family history of alcoholism during an interactive competitive fMRI task. PLoS One, 9:e88188. 
Zhou, Z., Yuan, G., \& Yao, J., 2012. Cognitive biases toward Internet game-related pictures and executive deficits in individuals with an Internet game addiction. PLoS.One., 7, e48961. 